\title{
UTJECAJ TRETIRANJA SJEMENA STIMULATOROM KLIJANJA EKOBOOSTER 1 NA POČETNI RAST I RAZVOJ PAPRIKE
}

\author{
Marina PALFI, Z. MATOTAN, Svjetlana MATOTAN \\ Podravka d.d., Koprivnica, Istraživanje i razvoj, Razvoj poljoprivrede \\ Podravka d.d. Koprivnica, Research and Development, Agricultural Development
}

\begin{abstract}
SAŽETAK
Provedenim istraživanjem pokušalo se ustanoviti djelovanje stimulatora klijanja EkoBooster 1 na početni rast i razvoj paprike.

Ispitivanja su provedena na sjemenu paprike sorte Podravka $\mathrm{u}$ laboratorijskim uvjetima na filter papiru pri temperaturama $20^{\circ} \mathrm{C}$ i $20-30^{\circ} \mathrm{C}$. Sjeme paprike tretirano je 1\%-tnom otopinom preparata EkoBooster $1 \mathrm{u}$ trajanju od 20 minuta.

Kod energije klijanja sjemena nije uočena statistički značajna razlika između sjemena tretiranog stimulatorom klijanja i netretiranog sjemena niti na jednoj razini temperature, ali je zato klijavost sjemena povećana kod sjemena tretiranog stimulatorom klijanja na obje razine temperatura. Klijavost je kod netretiranog sjemena $u$ odnosu na sjeme tretirano stimulatorom klijanja pri temperaturi ispitivanja od $20^{\circ} \mathrm{C}$ bila manja za $9 \%$, a pri temperaturi od $20-30^{\circ} \mathrm{C}$ za $4 \%$. Postotak nenormalnih klijanaca i neklijavog sjemena je smanjen u odnosu na netretirano sjeme. Masa svježih i zdravih klijanaca povećana je na obje razine temperatura ispitivanja u odnosu na netretirano sjeme.

Temeljem rezultata provedenih istraživanja može se zaključiti da tretman sjemena stimulatorom klijanja daje pozitivne učinke na ispitivana svojstva što je naročito značajno u uvjetima nepovoljnih temperatura u početnim fazama razvoja paprike.
\end{abstract}

Ključne riječi: paprika, stimulator klijanja, klijavost, temperatura

\section{UVOD}

Paprika (Capsicum annuum L.) je povrtna kultura izuzetno visokih zahtjeva prema toplini. Najbrže klijanje i nicanje je pri temperaturama $25-30^{\circ} \mathrm{C}$, a minimalna temperatura pri kojoj sjeme može klijati je $11^{\circ} \mathrm{C}$ (Matotan, 2004). Zbog mogućih niskih temperatura $\mathrm{u}$ početku klijanja i nicanja sjemena paprike poželjno je pomoći sjemenu da što prije proklije. Nejednoliko klijanje i nicanje naročito je izraženo kod 
M. Palfi i sur.: Utjecaj tretiranja sjemena stimulatorom klijanja

Ekobooster 1 na početni rast i razvoj paprike

izravne sjetve paprike jer su temperature tla često ispod optimalne vrijednosti (O'Sullivan i Bouw, 1984). Provode se mnoga istraživanja u cilju pronalaska načina koji će omogućiti brže klijanje sjemena poljoprivrednih kultura i omogućiti mladim biljčicama uvjete brzog rasta i razvoja (Yildirimi sur. 2007; Palfi, 2007; Parađiković i sur., 2008a; Jankauskienè i Survilienè, 2009; Miladinov i sur., 2014; Lisjak i sur., 2015; Eremrena i Mensah, 2016).

Jedan od načina stimulacije bržeg klijanja i nicanja sjemena i poboljšanog rasta i razvoja mladih biljčica je primjena biostimulatora. Biostimulatori su tvari koje poboljšavaju imunološki sistem biljaka i pozitivno djeluju na njihov metabolizam (Kolomazik i sur., 2012). a mogu pomoći biljkama prevladati stresne situacije (Ertani i sur., 2013). Upotreba biostimulatora primijenjenim na sjeme može osigurati pozitivne učinke u fiziološkoj kvaliteti sjemena proizvedenog u slijedećoj generaciji (Neta i sur., 2016)

Biostimulatori mogu sadržavati: huminske kiseline, hormone, aminokiseline i druge fiziološki aktivne tvari (vitamini, polisaharidi i drugo), pojedinačno ili $u$ kombinaciji (Zeljković i sur., 2013). Biostumulatori potiču rast i razvoj biljaka, pozitivno utječu na razvoj korijena te omogućuju smanjenu uporabu fungicida što ih čini privlačnim zbog očuvanja okoliša (Calvo i sur., 2014).

Cilj provedenog istraživanja bio je utvrditi utjecaj biostimulatora EkoBooster $1 \mathrm{na}$ početni rast i razvoj paprike (Capsicum annuum L.) u laboratorijskim uvjetima.

\section{MATERIJAL I METODE RADA}

Ispitivanja su provedena $\mathrm{u}$ laboratoriju za ispitivanje sjemena Podravka d.d. Koprivnica na sjemenu paprike sorte Podravka. Sjeme paprike tretirano je 1\%-tnom otopinom preparata EkoBooster 1 tvrtke Ekopatent u trajanju od 20 minuta.

EkoBooster 1 je organsko gnojivo - biostimulator-bio regulator, preparat koji je namijenjen obradi sjemena i jačanju korjenovog sistema tijekom ukorjenjavanja biljke. Sadrži 2,8\% organske tvari, 14\% N, 2\% P i 5\% K.

U svrhu izvođenja istraživanja sjeme paprike je stavljeno u Petrijeve zdjelice na dvoslojni filter papir koji je prethodno navlažen 0,2\%-tnom vodenom otopinom kalijevog nitrata $\left(\mathrm{KNO}_{3}\right)$ prema Pravilniku o metodama uzorkovanja i ispitivanja kvalitete sjemena (NN 9/08). Naklijavanje sjemena paprike provedeno je na temperaturama od $20^{\circ} \mathrm{C}$ i izmjeničnim temperaturama $20-30^{\circ} \mathrm{C}$ u klima komori Binder KBW 100, pri svjetlosnom režimu $12 \mathrm{~h}$ dan/12 h noć.

Sedmi dan nakon postavljanja sjemena na nakljavanje očitavala se energija klijanja, a nakon 14 dana klijavost sjemena, nenormalni klijanaci i neklijavo sjeme. Svaka varijanta je postavljena u 4 ponavljanja po 100 sjemenki. Rezultati energije klijanja, klijavosti, nenormalnih klijanaca i neklijavog sjemena izraženi su u postotcima. Masa svježih i zdravih klijanaca mjerila se zadnji dan nakon ispitane klijavosti i 
izražena je u gramima. Ispitivanja su izvršena na sjemenu paprike čija su čistoća, masa 1000 sjemenki i vlaga prikazani u Tablici 1.

Dobiveni rezultati statistički su obrađeni dvosmjernom analize varijance (ANOVA) pomoću statističkog programa GraphPadPrizm. Razlike su procijenjene pomoću testa višestruke usporedbe. Rezultati su smatrani statistički značajnim ako je $\mathrm{P}<0,05$.

Tablica 1. Parametri kvalitete sjemena s kojim su provedena istraživanja

Table 1 Seed quality parameters used in investigations

\begin{tabular}{cccc}
\hline $\begin{array}{c}\text { Sorta } \\
\text { Variety }\end{array}$ & $\begin{array}{c}\text { Čistoća sjemena (\%) } \\
\text { Purity of seeds (\%) }\end{array}$ & $\begin{array}{c}\text { Masa 1000 sjemenki (g) } \\
1000 \text { seeds weight }(g)\end{array}$ & $\begin{array}{c}\text { Vlaga sjemena (\%) } \\
\text { Seeds moisture (\%) }\end{array}$ \\
\hline Podravka & 99,2 & 6,61 & 10,3 \\
\hline
\end{tabular}

\section{REZULTATI I DISKUSIJA}

Tretman sjemena paprike biostimulatorom EkoBooster 1 kod energije klijanja nije pokazao statistički značajne razlike između sjemena tretiranog stimulatorom klijanja i netretiranog sjemena niti na jednom temperaturnom režimu (Slika 1).

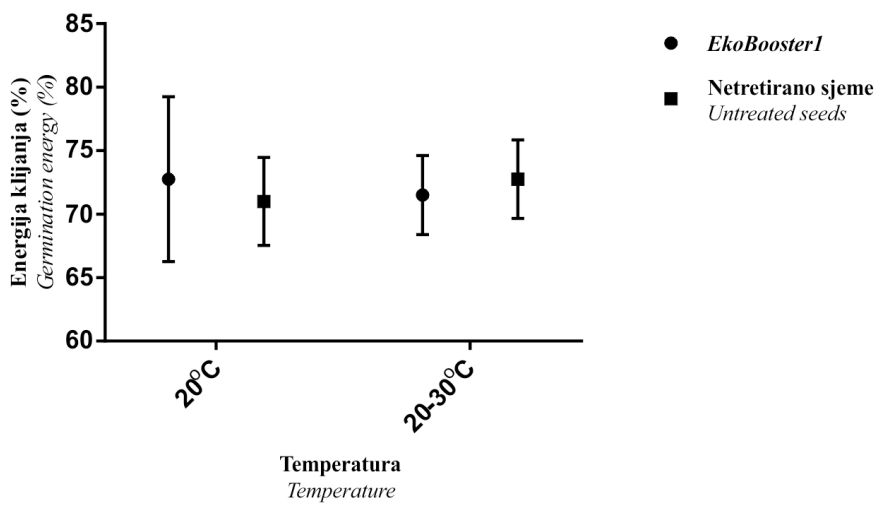

Slika 1. Utjecaj tretmana sjemena biostimulatorom EkoBooster 1 na energiju klijanja

Figure 1 Effect of seed treatment with biostimulant EkoBooster 1 on germination energy 
Klijavost sjemena tretiranog stimulatorom klijanja povećana je i na nižoj i na višoj razine temperature. Statistički značajne razlike $(\mathrm{P}<0,05)$ ustanovljene su između sjemena tretiranog biostimulatorom klijanja EkoBooster 1 i netretiranog sjemena pri nižoj temperaturi $\left(20^{\circ} \mathrm{C}\right)$ (Slika 2$)$.

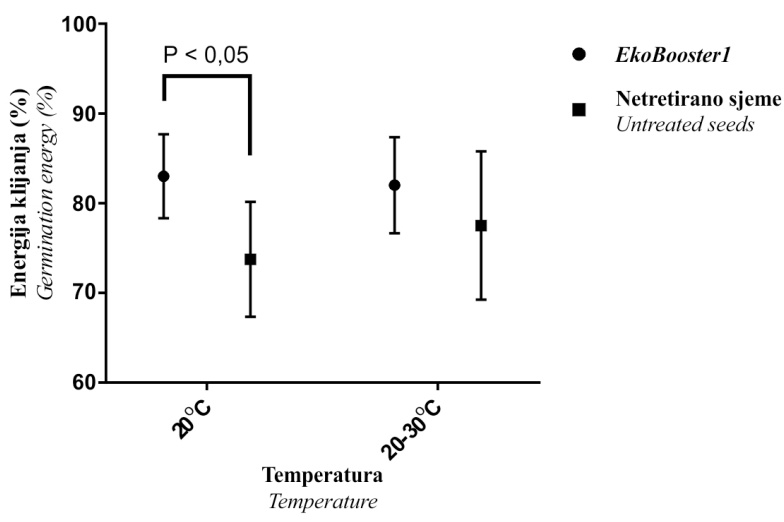

Slika 2. Utjecaj tretmana sjemena biostimulatorom EkoBooster 1 na klijavost sjemena

Figure 2 Effect of seed treatment with biostimulant EkoBooster 1 on seed germination

Klijavost je kod netretiranog sjemena u odnosu na sjeme tretirano stimulatorom klijanja pri temperaturi ispitivanja od $20^{\circ} \mathrm{C}$ bila manja za $9 \%$, a pri temperaturi od $20-30^{\circ} \mathrm{C}$ za $4 \%$. Iako je postotak nenormalnih klijanaca bio niži za $3 \%$ kod sjemena tretiranog biostimulatorom klijanja nego netretiranog sjemena nije ustanovljena statistički značajna razlika niti kod jedne razine temperatura (Slika 3).

Postotak neklijavog sjemena je smanjen kod sjemena tretiranog biostimulatorom klijanja u odnosu na netretirano sjeme i kod više i kod niže ispitivane temperature, ali je statistički značajna razlika $(\mathrm{P}<0,05)$ ustanovljena samo kod niže temperature (Slika 4).

Smanjenje postotka neklijavog sjemena kod sjemena tretiranog biostimulatorom na nižoj temperaturi iznosila je $6 \%$ što je bilo i za očekivati budući da su dobiveni rezultati pokazali povećanje klijavosti takvog sjemena. 


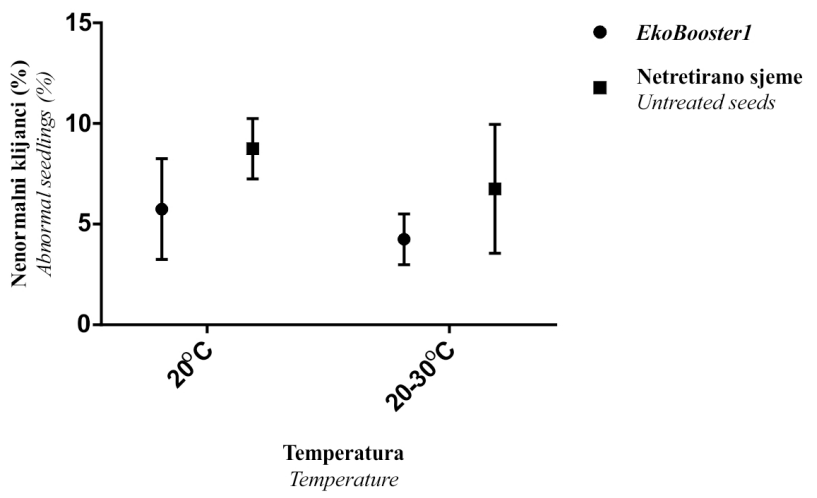

Slika 3. Utjecaj tretmana sjemena biostimulatorom EkoBooster 1 na postotak nenormalnih klijanaca Figure 3Effect of seed treatment with biostimulant EkoBooster 1 on percentage of abnormal seedlings

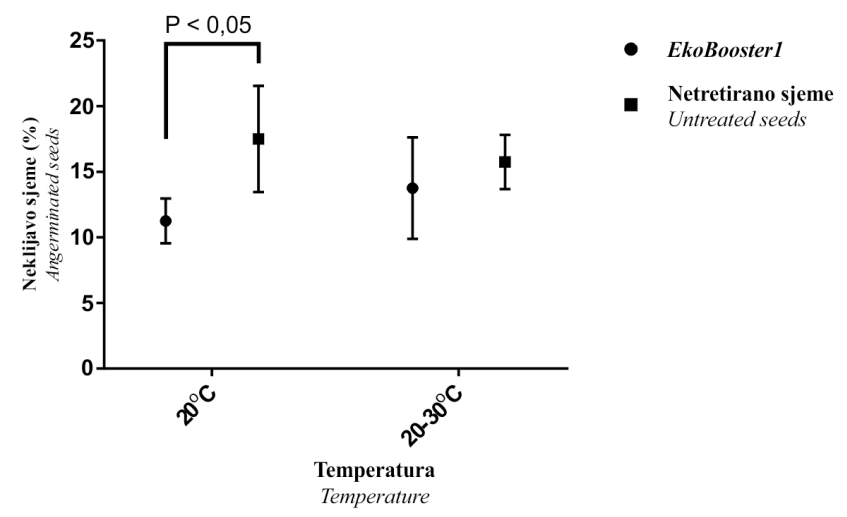

Slika 4. Utjecaj tretmana sjemena biostimulatorom EkoBooster 1 napostotak neklijavog sjemena Figure 4 Effect of seed treatment with biostimulant EkoBooster 1 on the percentage ungerminated seeds

Dobiveni rezultati su u skladu s ispitivanjima Miladinov i sur. (2015) koji su ustanovili da je tretiranje sjemena biostimulatorima prije sjetve imalo značajan utjecaj na parametre klijanja i početni porast suncokreta. Autori su ustanovili da se primjenom biostimulatora može povećati energija klijanja za $5 \%$, klijavost za $6 \%$, ali i skratiti 
vrijeme klijanja sjemena. Jankauskienè i Survilienè (2009) su dokazali da je primjena biostimulatora utjecala na povećanje klijavost sjemena rotkvice i rajčice za 10 $30 \%$. Parađiković i sur. ( 2008a) su ustanovili da je tretman sjemena cvjetnih vrsta dao pozitivan učinak na energiju klijanja, ali se kod klijavosti taj pozitivan učinak gubi za razliku od naših rezultata gdje je ustanovljen pozitivan učinak kod klijavosti sjemena, ali ne i kod energije klijanja.

Miladinov i sur. (2014) došli su do zaključka da se energija klijanja i klijavost sjemena može smanjiti nepravilnim izborom biostimulatora odnosno lošom kombinacijom.

Rezultati provedenih istraživanja ukazuju da je masa svježih i zdravih klijanaca povećana na svim temperaturama ispitivanja u odnosu na netretirano sjeme, ali je kao i kod ispitivanja klijavosti sjemena statistički značajna razlika $(\mathrm{P}<0,05)$ ustanovljena kod niže temperature (Slika 5).

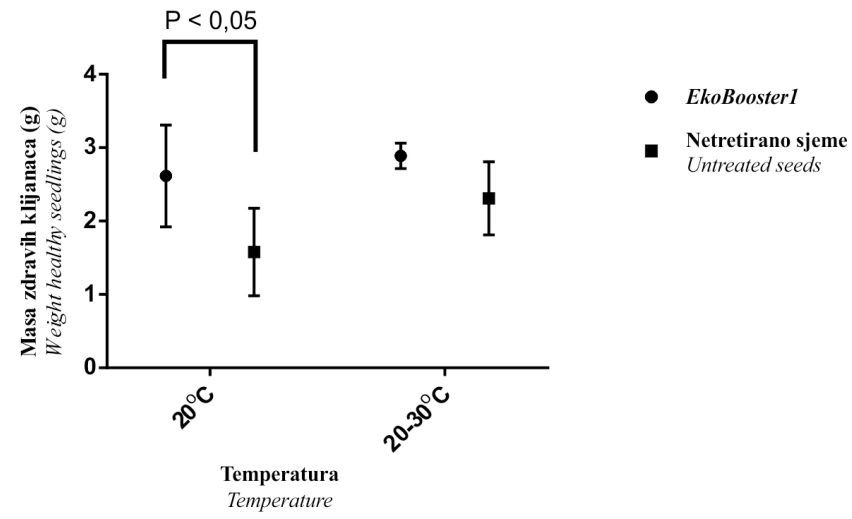

Slika 5. Utjecaj tretmana sjemena biostimulatorom EkoBooster 1 na masu zdravih klijanaca Figure 5 Effect of seed treatment with biostimulant EkoBooster 1 on weight healthy seedlings

Dobiveni rezultati su u skladu s ispitivanjima Parađiković i sur. (2008a) koji su ustanovili da je masa svježe i suhe tvari klijanaca cvjetnih vrsta gotovo uvijek bila viša kod tretmana sa biostimulatorom. Autori ističu da biostimulatori na bazi huminskih kiselina, aminokiselina, proteina, peptida, polisaharida i vitaminskog kompleksa, pomažu razvoj korijena i povećavaju njegovu otpornost u uvjetima zaslanjenog zemljišta ili tla tretiranog pesticidima.

Istraživanja su pokazala da humusna i fulvinska kiselina značajno utječu na povećanje energije klijanja sjemena, intenziviranje rasta sadnica, rasta i težine korijena 
M. Palfi i sur.: Utjecaj tretiranja sjemena stimulatorom klijanja

Ekobooster 1 na početni rast i razvoj paprike

(Katkat i sur., 2009; Matysiak i sur, 2011). Ustanovljeno je da primjena biostimulatora povećava masu svježe i suhe mase klijanaca kod soje i kukuruza (Vinković i sur., 2007) i pozitivno djeluje na razvoj korijena u proizvodnji presadnica rajčice i proizvodnji suncokreta (Parađiković i sur., 2008b; Miladinov i sur., 2015). Istraživanja Zeljković i sur. (2014) ukazuju da primjena biostimulatora u proizvodnji presadnica bosiljka poboljšava rast i razvoj korijena i nadzemnog dijela što je naročito važno za bolju i bržu adaptacije biljaka na stres uslijed presađivanja. Primjena biostimulatora u kombinaciji s načinom uzgoja pozitivno utječe na vegetativni razvoj listova te time omogućuje veću produktivnost biljke kroz pojačanu fotosintezu i transpiraciju (Vinković, 2013).

\section{ZAKLJUČAK}

Temeljem rezultata provedenih istraživanja ustanovljeno je da tretman sjemena biostimulatorom Ekobooster 1 daje pozitivne učinke na klijavost sjemena i masu svježih i zdravih klijanaca paprike, naročito kod temperature od $20^{\circ} \mathrm{C}$ što je za posljedicu imalo smanjenje postotka neklijavog sjemena. Pri višoj temperaturi pozitivan učinak na ispitivane parametre kvalitete nije bio toliko izražen. Iz svega navedenog može se zaključiti da tretman sjemena biostimulatorom Ekobooster 1 može pomoći u početnim fazama razvoja paprike, naročito u uvjetima nepovoljnih temperatura.

\section{EFFECT OF SEED TREATMENT BY GERMINATION STIMULATE EKOBOOSTER 1 ON THE INITIAL GROWTH AND DEVELOPMENT OF PEPPER}

\section{SUMMARY}

The research was attempted to determine the effect of germination stimulator EkoBooster 1 on the early growth of peppers.

Research were conducted on the seed of pepper variety Podravka in laboratory conditions on filter paper at temperatures of $20^{\circ} \mathrm{C}$ and $20-30^{\circ} \mathrm{C}$. Seeds of pepper were treated with $1 \%$ solution of the preparation EkoBooster 1 for 20 minutes.

For germination energy of seeds statistically no significant difference between the treated seed with germination stimulator and untreated seeds at any temperature was founded, but the seed germination was increased with seed germination stimulator treated at lower and higher temperatures. Germination of untreated seeds and the seeds treated with the germination stimulator at a test temperature of $20^{\circ} \mathrm{C}$ was reduced by $9 \%$ and at 
temperature of $20-30^{\circ} \mathrm{C}$ to $4 \%$. The percentage of abnormal seedlings and angerminated seeds is increased at all temperatures regime compared to untreated seed. The mass of fresh and healthy seedlings developed from treated seeds are increased at all temperatures tests compared to untreated seed.

Based on the results of research it can be concluded that the treatment of seed germination stimulator gives positive effects on the tested properties which is particularly significant in the context of unfavorable temperature in the initial stages of pepper development.

Key words: pepper, stimulator of germination, germination, temperature

\section{LITERATURA - REFERENCES}

1. Calvo, P., Nelson, L., Kloepper, J. W. (2014): Agricultural uses of plant biostimulants. Plantand Soil, 383 (1-2): 3-41.

2. Eremrena, P. O., Mensah, S. I. (2016): Effect of plant growth regulators and nitrogenous compounds on seed germination of pepper (Capsicum frutescens L). J. Appl. Sci. Environ. Manag., 20 (2): 242-250.

3. Ertani, A., Schiavon, M., Muscolo, A., Nardi, S. (2013): Alfalfa plant-derived biostimulant stimulate short-term growth of saltstressed Zea mays L. plants. Plant and soil, 364 (12): $145-158$.

4. Ek oB o o st er-http://www.ekopatent.biz/wordpress/galerija/ekobooster-1//, pristupljeno 17.01.2014.

5. Graph - PadSoftware, San Diego, CA, USA. Available online: http://www.graphpad.com, pristupljeno 26. 11. 2013.

6. Jankauskienè, J. i Survilienè, E. (2009): Influence of growth regulators on seed germination energy and biometrical parameters of vegetables. Sodininkystė ir daržininkystė, 28(3): $69-77$.

7. Katkat, A. V., Celik, H., Turan, M. A., Asik, B. B. (2009): Affects of soil and foliar application sofhumic substances on dry weight and mineral nutrients up take of wheat under calcareoussoil conditions. Austr. J. Basic Appl. Sci., 3 (2): 1266-1273.

8. Kolomaznik, K., Pecha, J., Friebrovà, V., Janàčovà, D., V ašek, V. (2012): Diffusion of biostimulators in to plant issues. Heat and Mass Transfer, 48 1505-1512.

9. Lisjak, M., Tomić, O., Špoljarević, M., Teklić, T., Stanisavljević, A., Balas, J. (2015): Garden cress germinability and seedling vigour after treatment with plant extracts. Poljoprivreda, 21 (2): 41-46.

10. Matotan, Z., (2004): Suvremena proizvodnja povrća. Nakladni zavod Globus, Zagreb.

11. Matysiak, K., Kaczmarek, S. Krawczyk, R. (2011): Influence of sea weed extract sand mixture of humic and fulvicacids on germination and growth of Zea mays. L. Acta Sci. Pol., Agricultura., 10 (1): 33-45.

12. Miladinov, Z. J., Balalić, I. M., Radić, V. B., Crnobarac, J. Ž., Jocković, M. Đ., Jokić, G. O., Miklič, V. J. (2015): Uticaj biostimulatora na klijanje i rani porast klijanca suncokreta. J. Agri. Sci., 60 (1): 1-9.

13. Miladinov, Z., Radić, V., Miklič, V., Crnobarac, J., Balalić, I., Jocković, M., Mrđa, J. (2014): Uticaj biostimulatora na energiju klijanja i klijavost semena suncokreta. Ratarstvo i povrtarstvo, 51:29-37. 


\section{Palfi i sur.: Utjecaj tretiranja sjemena stimulatorom klijanja Ekobooster 1 na početni rast i razvoj paprike}

14. Neta, M. L. D. S., Oliveira, F. D. A. D., Torres, S. B., Souza, A. A. T., Carvalho, S. M. C., Benedito, C. P. (2016): Residual effect of burgherkin seed treatment with biostimulant under salt stress. J. Seed Sci., 38(3): 219-226.

15. O'Sullivan, J. i Bouw, W. J. (1984): Pepper seed treatment for low-temperature germination. Can. J. Plant Sci., 64: 387-393.

16. Palfi, M. (2007): Skarifikacija sjemena lucerne (Medicago sativa L.) kiselinom. Sjemenarstvo, 24(1): 5-16.

17. Parađiković, N., Vinković, T., Radman, D. (2008a): Utjecaj biostimulatora na klijavost sjemena cvjetnih vrsta. Sjemenarstvo, 25(1): 25-33.

18. Parađiković, N., Vinković, T., Teklić, T., Guberac, V., Milaković, Z., (2008b): Primjena biostimulatora u proizvodnji presadnica rajčice. 43. Hrvatski i 3. Međunarodni Simpozij Agronoma. Zbornik radova, 435-439.

19. Pravilnik o metodama uzorkovanja i ispitivanja kvalitete sjemena (NN 99/08)

20. Vinković, T., Parađiković, N., Plavšić, H., Guberac, V., Levai, L. (2007). Maize and soybean seed vigour under influence of seed age, seed treatment and temperature in cold stress test. Cereal Res. Commun., 35(2):1213-1216.

21. Vinković, T., Parađiković, N., Teklić, T., Tkalec, M., Josipović, A. (2013): Utjecaj biostimulatora na indeks lisne površine kod rajčice. In 48th Croatian \& 8th International Symposium on Agriculture, Dubrovnik, Croatia.

22. Yildirim, E., Dursun A., Guvenc, I., Kumlay A. M. (2007):. The effects of different salt, biostimulant and temperature levels on seed germination of some vegetable species. II Balkan Symposium on Vegetables and Potatoes. ActaHorticulturae, 579: 249-253.

23. Zeljković, S., Parađiković N., Šušak, U., Tkalec, M. (2014): Rast i razvoj rasada bosiljka (Ocimum basilicum L.) pod utjecajem biostimulatora. Agroznanje, 15(4): 415-424.

Adresa autora - Author's address:

Mr. sc. Marina Palfi

Mr. sc. Svjetlana Matotan

Dr. sc. Zdravko Matotan

Podravka d.d. Koprivnica

Ante Starčevića 32

48000 Koprivnica

Hrvatska

E-mail: marina.palfi@podravka.hr
Primljeno - Received:

02. 01. 2017. 
